\title{
SUCCESS RATES OF CALCIUM-HYDROXIDE-IODOFORM PASTE IN VITAL PULPOTOMY OF PRIMARY MOLARS
}

\author{
Hany Mohamed Saber* and Samah Mohamed Awad ${ }^{* *}$
}

\begin{abstract}
Background: Despite customary utilization of calcium-hydroxide-iodoform-paste in treatment of necrotic primary teeth few studies reported its use in vital pulpotomy.

Aim: This longitudinal study aimed to evaluate success rates of primary molars treated with vital pulpotomy (VP) using calcium-hydroxide-iodoform-paste and stainless steel crowns (SSC) to those subjected to cavity preparations $(\mathrm{CP})$ \& compomer restorations $(\mathrm{CM})$.

Design: Eighty molars were subjected to either VP $(n=40)$ or CP-applying double bond$(n=40)$. Split mouth technique was employed. Medically free children aged four to eight years old possessing carious lower second primary comprised inclusion criteria. Treated molars were followed up 3, 6 \& 12 months. Treated molars were considered clinically successful when free from pain, abscess and/ or abnormal mobility. When either internal (IR) or external (ER) root resorption, periapical (PR) or inter-radicular (IRR) radiolucency was encountered, radiographic failure was recorded. Chi square test was used for data analysis.
\end{abstract}

Results: Clinical success was evident in $97.5 \%(n=39)$ of cases treated by VP whereas failure in the form of abscess was noted in $2.5 \%(\mathrm{n}=1)$ which was statistically insignificant $(\mathrm{p}=0.33)$. Radiographically, success was shown in $75 \%(n=30)$ whereas failure was noted in $25 \%(n=10)$ out of which IR, ER and IRR represented $7.5 \%(n=3), 15 \%(n=6)$ and $2.5 \%(n=1)$ respectively. Molars treated by $\mathrm{CP}$ showed neither clinical nor radiographic signs of failure. No significant difference was noted comparing results of molars treated by VP to CP clinically $(\mathrm{p}=0.314)$ whereas significant difference was noted radiographically $(\mathrm{p}=0.001)$.

Conclusion: Calcium-hydroxide-iodoform-paste proved to be successful in treatment of vital primary molars.

\section{INTRODUCTION}

Adistinct rational of pediatric dentistry is to retain primary teeth perfectly functional in the dental arch.
This is important to provide proper mastication, decent aesthetics, speech development as well as space preservation. (1) Caries management of primary dentition affords different sets of challenges

*Lecturer-Pediatric Dentistry \& Dental Public Health Department, Faculty of Dentistry, Cairo University. ** Associate Professor-Pediatric Dentistry \& Dental Public Health Department, Faculty of Dentistry, Cairo University. 
and treatment opportunities. The continuum of care depends on several factors including the extent of insult or dental decay. ${ }^{(2)}$

The concept of modern cavity preparation dictates merely eradicating lesions without any further extension or destruction of sound tooth structure. It relies on the adhesive properties of aesthetic restorations in retention. ${ }^{(3)}$

Vital pulp therapy is advocated when decayed primary molars possess vital pulp or reversible pulpitis is encountered. Thereby, the tooth -that would otherwise get extracted- is retained and the active disease is eliminated. ${ }^{(4)}$ Pulpotomy is the most frequent treatment of carious primary molars. This treatment modality involves removal of coronal pulp tissue and retaining pulp in root canals assuming that left over radicular pulp is quite intact. ${ }^{(2,4)}$

Formocresol has been a 'benchmark medicament' for pulpotomy to which various agents were compared to. ${ }^{(5)}$ However, due to concerns regarding its possible carcinogenic and other deleterious effects, ${ }^{(6-8)}$ alternative agents has been subjected to research.

On the other hand, literature had provided suggestions for mixing calcium hydroxide with other substances in order to enhance some properties as antibacterial action, radiopacity and consistency. ${ }^{(9,10)}$

Calcium hydroxide iodoform paste is a premixed paste which contains mainly iodoform presenting $40.4 \%$, in addition to $30.3 \% \mathrm{Ca}(\mathrm{OH})_{2}, 22.4 \%$ silicon oil and $6.9 \%$ inert materials. ${ }^{(11)}$ Though this paste was successfully utilized in treating non-vital primary teeth, ${ }^{(11-14)}$ to the best of our knowledge studies on its use in vital primary teeth are still scarce.

\section{Aim of the study:}

To evaluate clinically \& radiographic success of primary molars treated with vital pulpotomy
(VP) using calcium hydroxide-iodoform paste and restored by stainless steel crowns (SSC) to those subjected to cavity preparations (CP) \& finally restored by compomer restorations $(\mathrm{CM})$.

\section{SUBJECTS AND METHODS}

\section{Subjects and Study Settings:}

The current study recruited patients aged 4-8 years old attending clinics in Pediatric Dentistry and Dental Public Health Department - Faculty of Dentistry - Cairo University. The study was approved by the Ethical Committee and an informed consent was obtained from each parent. Patients were either included or excluded according to the following criteria.

\section{Inclusion Criteria:}

1. Apparently free from any systemic disease.

2. Patients presented by bilateral carious lower second primary molars where one of them was indicated for pulpotomy and the other was indicated for cavity preparation.

3. Clinically, primary molars with deep carious lesions without presence of soft tissue abscess, sinus tract or fistula were included.

\section{Exclusion Criteria:}

1. Reported history of spontaneous pain.

2. Clinical signs of necrotic primary molars.

3. Radiographic signs of root resorption, or furcation/periapical radiolucencies.

4. Unrestorable molars.

\section{Methods:}

\section{Vital pulpotomy:}

This involved removal of coronal pulp tissue from pulp chamber till entrances of root canals. Local anesthesia was administered. This was followed by proper isolation and caries removal. 
Coronal access was then performed using highspeed hand piece. Removal of coronal pulp tissue from pulp chamber was performed by a sharp excavator. Bleeding was controlled by a wet cotton pellet followed by placement of calcium hydroxide iodoform (Metapex) shown in Fig. (1) and stainless steel crown (3M- ESPE, USA) which was cemented by glass ionomer.

\section{Technique of Cavity preparation:}

This involved conservative cavity preparations to eradicate simple pit and fissure caries in affected lower second primary molars. Application of double layer of bonding agent (3M ESPE, USA) shown in Fig. (2) to the acid etched surface according to manufactures instructions. Then, they were restored by tooth-colored compomer (Twinky-star-Voco) shown in Fig. (3) as a final restoration.

\section{Follow up intervals:}

Treated children were recalled at 3,6 and 12 months postoperatively to assess their treated primary molars clinically (Figs. 4a\&b and Fig. 5a,b\&c) and radiographically (Figures 6a,b\&c) saccording to the set criteria. Extraction was planned to be carried out if clinical failure occurs in terms of evidence of pain, recurrent abscess and/ or abnormal mobility.

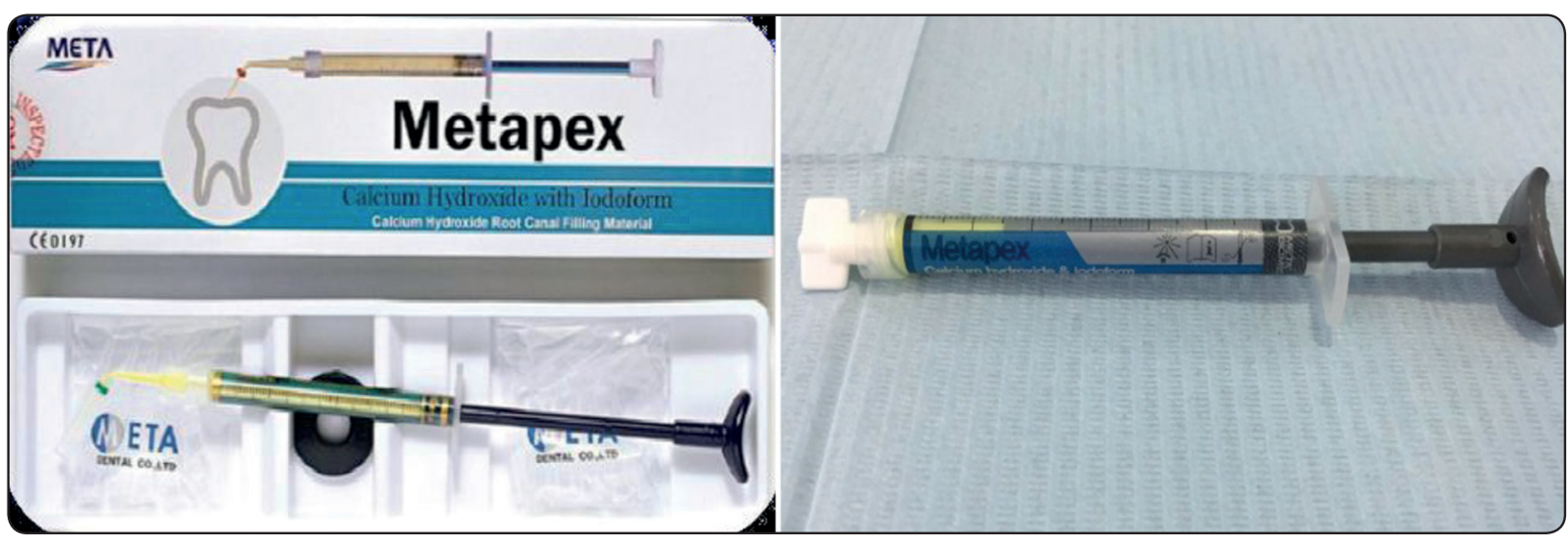

Fig. (1): Calcium Hydroxide iodoform (Metapex).

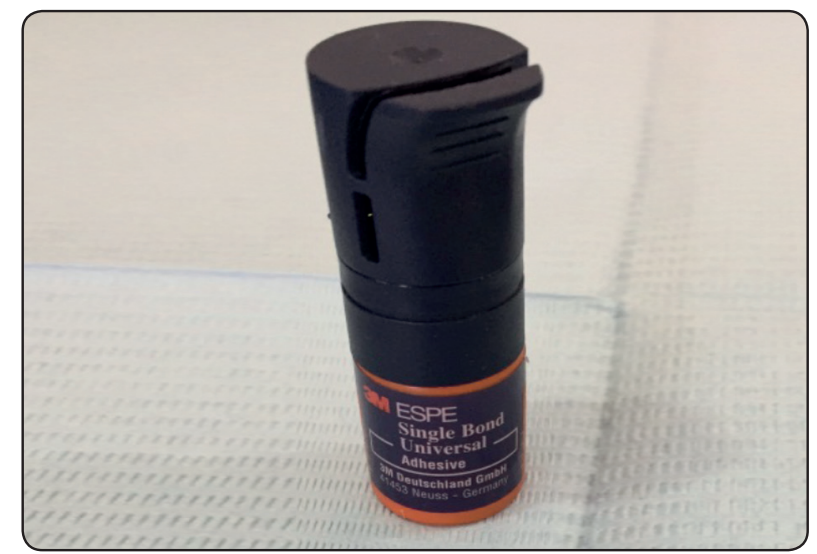

Fig. (2): Bonding agent (3M ESPE, USA).

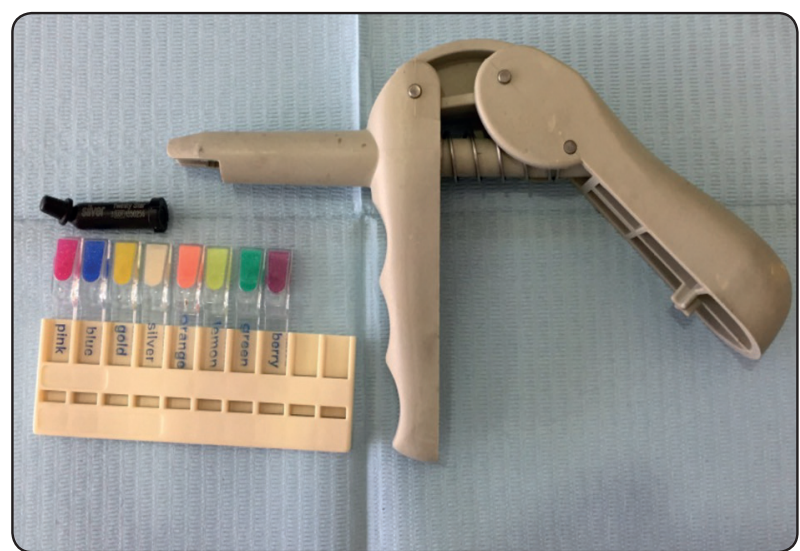

Fig. (3): Tooth-colored compomer (Twinky-star-Voco). 


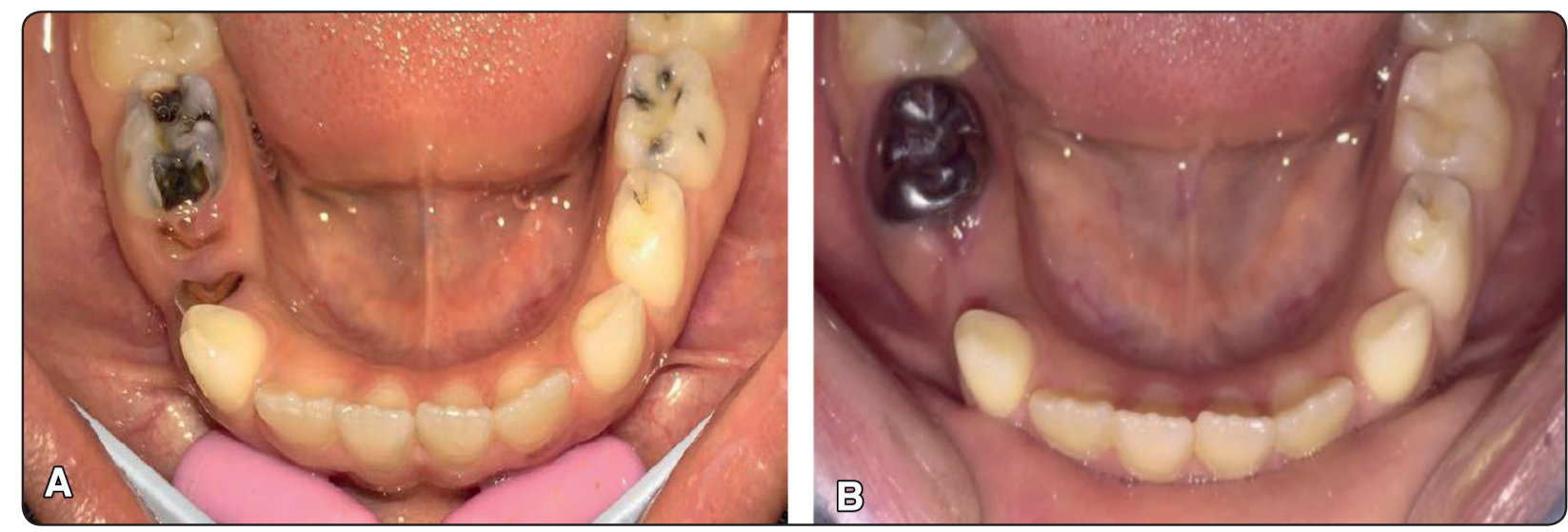

Fig. (4) (a): Preoperative clinical picture. (b): Postoperative clinical picture.

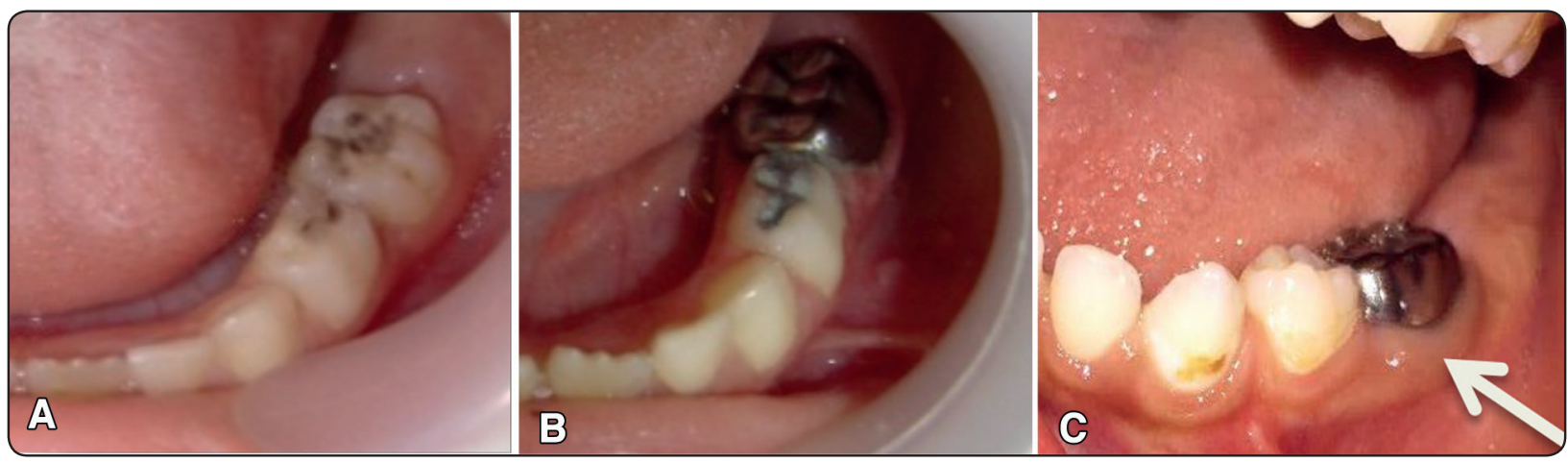

Fig. (5) (a): Preoperative clinical picture. (b): Postoperative clinical picture. (c) Postoperative clinical picture showing abscess.
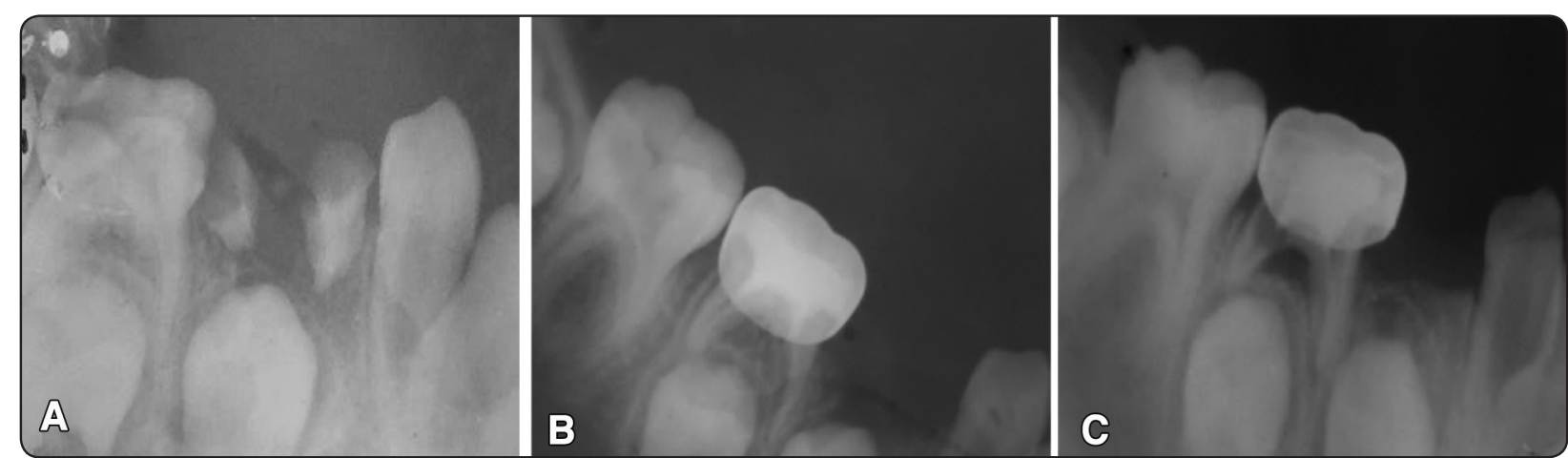

Fig. (6) (a): Preoperative radiograph. (b): Immediate postoperative radiograph. (c): Postoperative radiograph showing IRR.

\section{Criteria of evaluation:}

Treatment modality was considered successful when both clinical and radiographic examinations met the following during the follow up period:

- Clinically: when treated molars were completely free from; evidence of pain, swelling, abscess, tenderness to percussion and/ or abnormal mobility.

- Radiographically: when treated molars were completely free from; internal or external root resorption, any evidence periapical or inter-radicular radiolucency. 


\section{Sample Size:}

Calculation of sample size for the study using the Larry Connors method revealed that 80 primary second lower molars in 40 patients were required to be enrolled in the current study.

\section{Statistical Analysis:}

Data was collected and entered into the personal computer. Statistical analyses were done using Statistical Package for Social Sciences (SPSS/ version 20) software. Numbers and percentages for categorized parameters were calculated and compared using Chi square test. The level of significant was set to 0.05 .

\section{RESULTS}

Eighty lower second primary molars were treated in 40 patients. Males that had participated in the study comprised $57 \%(n=23)$ whereas females comprised $43 \%(n=17)$. Treatment modalities were assessed according to previously set criteria of evaluation in term of clinical and radiographic success.

Clinical success and failure in molars treated by VP and CP are presented in Table (1). Table (2) shows the type of clinical failure in molars treated by VP and CP. Radiographic success and failure in molars treated by VP and CP are presented in Table (3). Table (4) shows the type of clinical failure in molars treated by VP and CP.

TABLE (1) Comparison between VP and CP regarding clinical success and failure.

\begin{tabular}{|c|c|c|c|c|c|}
\hline & \multicolumn{2}{|c|}{ “VP" “n=40” } & \multicolumn{2}{c|}{ “CP” “n=40” } & \multirow{2}{*}{ p-value } \\
\cline { 2 - 5 } & Number & \% & Number & \% & \multirow{2}{*}{0.314} \\
\hline Clinical Success & 39 & 97.5 & 40 & 100.0 & 0.0 \\
\hline Clinical Failure & 1 & 2.5 & 0 & 0 \\
\hline
\end{tabular}

TABLE (2) Comparison between VP and CP regarding type of clinical failure.

\begin{tabular}{|c|c|c|c|c|c|}
\hline & \multicolumn{2}{|c|}{ "VP" "n=40" } & \multicolumn{2}{|c|}{ “CP" "n=40" } & \multirow{2}{*}{ p-values } \\
\hline & Number & $\%$ & Number & $\%$ & \\
\hline \multicolumn{6}{|c|}{ Type of clinical failure } \\
\hline Pain & 0 & 0.0 & 0 & 0.0 & - \\
\hline Abscess & 1 & 2.5 & 0 & 0.0 & 0.33 \\
\hline Mobility & 0 & 0.0 & 0 & 0.0 & - \\
\hline
\end{tabular}

TABLE (3) Comparison between VP and CP regarding radiographic success and failure.

\begin{tabular}{|c|c|c|c|c|c|}
\hline & \multicolumn{2}{|c|}{ "VP" “n=40" } & \multicolumn{2}{c|}{ “CP” “n=40” } & \multirow{2}{*}{ p-value } \\
\cline { 2 - 5 } & Number & \% & Number & \% & \multirow{2}{*}{$0.001 *$} \\
\hline Radiologic success & 30 & 75.0 & 40 & 100.0 & 0.0 \\
\hline Radiologic failure & 10 & 25.0 & 0 & \\
\hline
\end{tabular}


TABLE (4) Comparison between VP and CP regarding type of radiographic failure.

\begin{tabular}{|l|c|c|c|c|c|}
\hline \multirow{2}{*}{} & \multicolumn{2}{|c|}{ "VP" “n=40” } & \multicolumn{2}{c|}{ “CP” “n=40" } & \multirow{2}{*}{ p-values } \\
\cline { 2 - 6 } & Number & $\%$ & Number & $\%$ & \multicolumn{2}{c|}{$0.042 *$} \\
\hline Internal Resorption (IR) & 3 & 7.5 & 0 & 0.0 & $0.002 *$ \\
\hline External Resorption (ER) & 6 & 15.0 & 0 & 0.0 & 0.311 \\
\hline Inter-radicular Radiolucency (IRR) & 1 & 2.5 & 0 & 0.0 & 0.0 \\
\hline
\end{tabular}

\section{DISCUSSION}

The current study used a split-mouth design in order to compare more precisely the treatment modalities employed and to reduce specific variations that could influence the outcome. Each patient received both CP and VP in contralateral molars.

The results of the current study were in agreement with the results of Awad et al., $2013{ }^{(15)}$ where calcium hydroxide iodoform pulpotomy revealed 96\% clinical success and $88 \%$ radiographic success after 12 months postoperatively. This might be due to utilization of the same material, pulp condition of molars comprising the inclusion criteria as well as adopting the concurrent technique of pulpotomy employed in pediatric dentistry clinics in Cairo University.

Further, success results in the current study were higher than those encountered by El-Meligy, $2011^{(16)}$ who showed that clinical and radiographic success rates were $90 \%$ and $70 \%$ respectively. This might be due to the use of ferric sulfate -hemostatic agent- ahead of placement of calcium hydroxide and iodoform premixed paste in the study performed by El-Meligy which might had acted as protein barrier underneath the paste.

The results of the current study were higher than the study performed by Alacam et al., $2009^{(17)}$ who showed that clinical and radiographic success rates were $17.2 \%$ and $13.8 \%$ after 12 months respectively. This difference might be encountered as in the study performed by Alacam et al., $2009^{(17)}$, clinical procedures were carried out by fifth year undergraduate students, therefore different standards or different technique might had been performed.

In the current study, IR was categorized as a radiographic failure in accordance with El-Meligy, $2011^{(16)}$ and Awad et al., $2013^{(15)}$. In spite of being categorized under radiographic failure, treated molars possessing IR were further examined during successive follow-up periods to detect any sign of clinical failure. This came in accordance to Eidelman et al., 2001 ${ }^{(18)}$ and Alacam et al., $2009^{(17) .}$ Radiographic failures encountered in the current study were in the form of IR, ER and IRR. This was similar to radiographic failures shown by ElMeligy, 2011 ${ }^{(16)}$, but in contrast to the results of Awad et al., $2013^{(15)}$, in which IR was not reported. This contradiction might have occurred as the result of presence or absence of pre-existing inflammation of radicular pulp prior to treatment commencement.

According to the results of the current study, molars treated by $\mathrm{CP}$ showed neither clinical nor radiographic signs of failure. In addition, no statistical significant difference was noted comparing results of molars treated by VP to CP clinically, whereas, significant difference was noted on radiographic examination. This came in agreement with a randomized controlled study by Roberts, $2009^{(19)}$ which compared indirect pulp treatment 
(IPT) to VP using formocresol and revealed that clinical success rates of IPT were higher than that of VP. Further, it was shown that after more than 12 months (in 26 pairs of primary molars), statistical significant pathologic radiographic changes were encountered more in VP versus IPT. Hereafter, this might indicate that CP or IPT might be acceptable alternatives to VP in primary molars with carious lesions in a period of 12 months postoperatively.

\section{CONCLUSION}

1. Calcium hydroxide-iodoform paste has been proved to be successful in pulpotomy treatment in vital primary molars.

2. Cavity preparation followed by using double layer of bonding agent and compomer application showed excellent success rate.

\section{REFERENCES}

1- Ounsi HF, Debaybo D, Salameh Z, Chebaro A, Bassam H. Endodontic considerations in pediatric dentistry: A clinical perspective. Int Dent South Afr. 2009; 11: 40-50.

2- American Academy of Pediatric Dentistry (AAPD). Reference Manual 2013- 2014. Guidelines on Pulp Therapy for Primary and Immature Permanent Teeth.

3- Summitt JB. Conservative cavity preparations. Dent Clin North Am. 2002 Apr; 46(2):171-84.

4- Hill M.: The survival of vital and non- vital deciduous molar teeth following pulpotomy. Australian Dental Journal. 2007; 52: (3): 181-186.

5- Casas M, Kenny D, Johnston D, Judd P. Do we still need formocresol in pediatric dentistry? J Can Dent Assoc. 2005; 71: (10): 749 - 750 .

6- Lewis BB, Chestner SB. Formaldehyde in Dentistry: A review of mutagenic and carcinogenic potential. JADA 1981; 103: 429-434.

7- Zarzar P, Rosenblatt A, Takahashi C, Takeuchi P, Costa J. Formocresol mutagenicity following primary tooth pulp therapy: an in vivo study. J Dent 2003, 31(7):479 - 485.
8- Collins JJ, Lineker GA. A review and meta-analysis of formaldehyde exposure and leukaemia. Regulatory Toxicology and Pharmacology 2004; 40: 81-91.

9- Nurku C, Ranly D, Garcia-Godoy F, Lakshmyya K. Resorption of a calcium hydroxide/iodoform paste (vitapex) in root therapy for primary teeth: A case report. Pediatr Dent. 2000; 22: 6: 517- 520 .

10- Mortazavi M. and Mesbahi M. Comparison of zinc oxide and eugenol, and vitapex for root canal treatment of necrotic primary teeth. Int J Paediatr Dent. 2004; 14 (6): 417- 424.

11- Naidoo S. The Use of Calcium Hydroxide-Iodoform Paste in Pulpectomies. IADR- Federation Conference. September 2005. www.iadr.confex.com/iadr/afrmde05.

12- Trairatvorakul C. and Chunlasikaiwan S. Success of pulpectomy with zinc oxide and eugenol versus calcium hydroxide/iodoform paste in primary molars: A clinical study. Pediatr Dent. 2008; 30(4):303-308.

13- Farhad A, Esfahan Z. Calcium hydroxide: A review. Inter Dental Journal. 2005; 55: 293- 301.

14- Kavitha R. Clinical and radiographic evaluation of pulpectomies using zinc oxide and eugenol with iodoform, calcium hydroxide with iodoform, using zinc oxide and eugenol calcium hydroxide with iodoform. "Thesis", Submitted to Medical University-India, 2005. http://www.tnmmu.ac.in.

15- Awad S, Moheb D, Rashed M. Calcium Hydroxide Iodoform Paste in Vital Pulpotomy- Randomized Clinical Trial. IDJ Special Issue: Abstracts of the 101st FDI Annual World Dental Congress. September 2013, Volume 63, Issue Supplement1. http://onlinelibrary.wiley.com/ doi/10.1111/idj.2013.63.issue-s1/issuetoc

16- El-Meligy O. Clinical and radiographic evaluation of calcium hydroxide iodoform paste and formocresol pulpotomy techniques in primary teeth. Egyptian Dental Journal. 2011; 57: (2): 1181:1190.

17- Alacam A, Odabas M, Tuzuner T, Sillelioglu H, Baygin O. Clinical and radiographic outcomes of calcium hydroxide and formocresol pulpotomies performed by dental students. Oral Surg Oral Med Oral Pathol Oral Radiol Endod 2009; 108:127-133.

18- Eidelman E, Holan G, Fuks AB. Mineral trioxide aggregate vs. formocresol in pulpotomized primary molars: A preliminary report. Pediatr Dent 2001; 23:15-18.

19- Roberts JD. Indirect pulp treatment versus formocresol pulpotomy in human primary molars: A randomized controlled trial. Thesis. 2009. http://citeseerx .ist.psu.edu/viewdoc/download?doi=10.1.1.503.844\&rep=rep1\&type=pdf 